\title{
4D CITY TRANSFORMATIONS BY TIME SERIES OF AERIAL IMAGES
}

\author{
A. Adami \\ POLITECNICO DI MILANO, Department of Architecture, Built Environment and Construction Engineering, Milano, Italy - \\ andrea.adami@polimi.it
}

Commission V, WG V/4

KEY WORDS: city transformation, dense image matching, aerial images

\begin{abstract}
:
Recent photogrammetric applications, based on dense image matching algorithms, allow to use not only images acquired by digital cameras, amateur or not, but also to recover the vast heritage of analogue photographs. This possibility opens up many possibilities in the use and enhancement of existing photos heritage. The research of the original figuration of old buildings, the virtual reconstruction of disappeared architectures and the study of urban development are some of the application areas that exploit the great cultural heritage of photography.

Nevertheless there are some restrictions in the use of historical images for automatic reconstruction of buildings such as image quality, availability of camera parameters and ineffective geometry of image acquisition. These constrains are very hard to solve and it is difficult to discover good dataset in the case of terrestrial close range photogrammetry for the above reasons. Even the photographic archives of museums and superintendence, while retaining a wealth of documentation, have no dataset for a dense image matching approach.

Compared to the vast collection of historical photos, the class of aerial photos meets both criteria stated above. In this paper historical aerial photographs are used with dense image matching algorithms to realize $3 \mathrm{~d}$ models of a city in different years. The models can be used to study the urban development of the city and its changes through time. The application relates to the city centre of Verona, for which some time series of aerial photographs have been retrieved.

The models obtained in this way allowed, right away, to observe the urban development of the city, the places of expansion and new urban areas. But a more interesting aspect emerged from the analytical comparison between models. The difference, as the Euclidean distance, between two models gives information about new buildings or demolitions. As considering accuracy it is necessary point out that the quality of final observations from model comparison depends on several aspects such as image quality, image scale and marker accuracy from cartography.
\end{abstract}

\section{INTRODUCTION}

Nowadays it is widely acknowledged that artistic and cultural heritage of an urban centre is not only determined by its elements of greatest interest, the masterpieces, but also by the urban texture itself, the smaller building and its changes over time. So the study of urban transformations has become an important axis in the investigation of the city (Patias et al, 2011). In literature, there are examples of very different approaches and aims as concerning cultural heritage (El-Hakim et al, 2008), architectural transformations (Stefani et al, 2011), 4D city modelling and urban analysis (Schindler et al, 2012).

In parallel, a topic of great interest is the reconstruction of architectures and lost parts of the city, to provide new views to the visitor and the scholar (Pavlidis et al, 2010). In many cases the virtual reconstruction is based on verbal descriptions, drawings or depictions, however, it involves some uncertainty on the reliability of the result obtained. Another approach involves the reconstruction of the lost parts of the city through the procedural modelling (Ferdani et al, 2011)

Photogrammetry has always played a key role in the description of the city and its heritage and, after a period of relative disappearance, has returned to being considered a fundamental discipline for the survey and the study of urban centre. This revival is due to several aspects, but certainly a key element is the appearance of new software that automate the photogrammetric process, hence making it more affordable also to less specialized people. The meeting with computer vision has encouraged the spread of new digital photogrammetric software that allow to get three-dimensional models mapped with real textures in few steps.

The automation of these software also allows to recover a large part of the existing photographic heritage, from the most recent to the historical one, from terrestrial to aerial ones. Compared to other photogrammetric techniques, dense image matching allows the use of photographs of which some important parameters are unknown and to obtain directly a 3D model. So it is possible to study the development of city centre and also to build virtual reconstructions based on real data.

There are some restrictions in the use of all photographic heritage for automatic reconstruction of buildings. There are problems connected with the quality of photo itself, the limited number of shots and the geometry of acquisition.

These constrains are very hard to solve and it is difficult to discover good dataset in the case of terrestrial close range photogrammetry. Even the photographic archives of museums and superintendence, while retaining a wealth of documentation, have no dataset for a dense image matching approach.

Compared to the vast collection of historical photos, the class of aerial photos meets both criteria stated above. So they can be considered good candidates in the process to discover the urban transformation.

After an introduction about historical photographic heritage and the requirements of new photogrammetric software (based on dense image matching algorythm), this paper will describe 
the use of a time series of aerial images: the orientation based on cartographic coordinates, the calculation of models and their comparison. From the analysis of different model, some changes in the urban context will be evident and described.

\section{PHOTOGRAPHIC HERITAGE AND DENSE IMAGE MATCHING}

Many scientific papers describe the algorithms of dense image matching and the different approaches used (Haala, 2013). There are also many software which allow, by those algorithms, to build 3D models in an automatic way (Remondino et al, 2012) (Remondino et al, 2014). Although with slight differences, especially during the calculation of the features, orientation and triangulation, these software, both open source and commercial, have a similar behaviour and have the same requirements.

The advantages of these software in the use of historical images are concerning the automation of the process and the knowledge of parameters for orientation. In many cases there are no -or few- information about the images, above all as concerning the camera calibration. This often represents a problem with other techniques of digital photogrammetry. Moreover the use of such images in traditional photogrammetric software, based on DLT algorithm, requires much time to find the homologue points for orientation and then many points have to be extracted to build the $3 \mathrm{~d}$ model.

On the other side, these software work properly only under certain conditions. A first requirement concerns the quality of the photograph. As the feature recognition within the image is automatic (through algorithms SIFT, SURF, etc), it is necessary that the image is well-focused and that is not damaged (scratches or stains). Also the film grain is problem in this first stage as its points can be considered as feature to match.

Moreover as the orientation takes place through the matching of points of each photo, it is necessary that the shooting conditions are similar: it is not recommended to have shadows that change between images as the software tends to recognize them as different points. The images should be acquired by neighbouring points so as to allow the algorithm to identify the same point in a limited research area between images. Finally, to obtain a good orientation and the subsequent reconstruction, the software requires that images have a good overlap area in which the software can find homologous points.
In order to identify some datasets of images (both terrestrial and aerial) suitable for the reconstruction of missing parts of the city, several archives were visited, but it was very difficult to find a suitable set of photos.

The first problems affect precisely the photos themselves. The further you go back in time, the more the picture quality decreases and the effects of photographic grain are evident. In many cases the state of conservation is very inadequate and there are scratches, creases and stains on the photos themselves.

Another problem concerns the number of photos, especially the terrestrial ones. As it was a rather expensive practise, photographs were carefully chosen and were not taken more photographs than necessary: a photograph was often sufficient to document an architecture. This makes it difficult to find a set of photos large enough to allow a 3D reconstruction

Also with regards to the terrestrial photos, the geometry of acquisition represents a problem too. Perhaps for aesthetic reasons, the images were taken from the same positions, whereby, even in cases where they were available more shots, the geometry of the photographic shot was not suitable for three-dimensional reconstruction.

These observations do not apply with respect to the assets of aerial photographs. Especially aerial photos, captured with photogrammetric purposes, respond sufficiently to the requirements of the software dense image matching.

The flight pattern provides for a sufficient overlap of the images (at least $60 \%$ in the longitudinal direction and about 20 in the transverse direction). The pattern of the normal setting also allows a geometric regularity which facilitates the orientation of the frame.

There can be some problems, as presented in (Redecker, 2008), concerning the inaccuracy or total lack of metainformation about calibration (inner orientation and distortion, missing specification about the flight mission, poor radiometric image quality, distortions caused by roll and pitch due to sudden movements of the plane, improper storage of the film and inaccurate processing of original films.

Fortunately, as mentioned before, some information are not necessary in the recent photogrammetric software; instead remain the problems of photographic quality

On the whole Italian territory there are several archives of historical aerial photographs of great informational value. The most important collections include photos planimetric and stereoscopic taken between 1943 and 1945 by the scouts of the

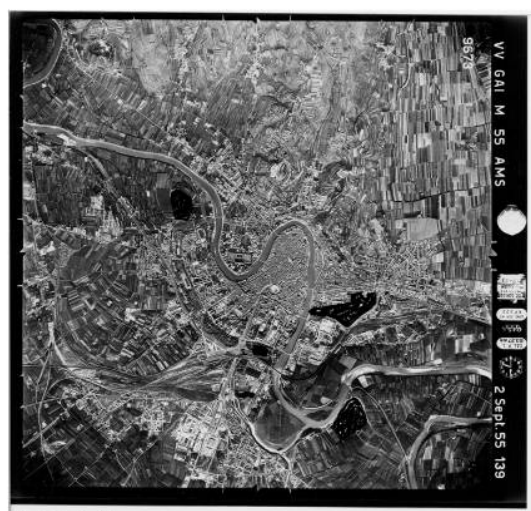

1954

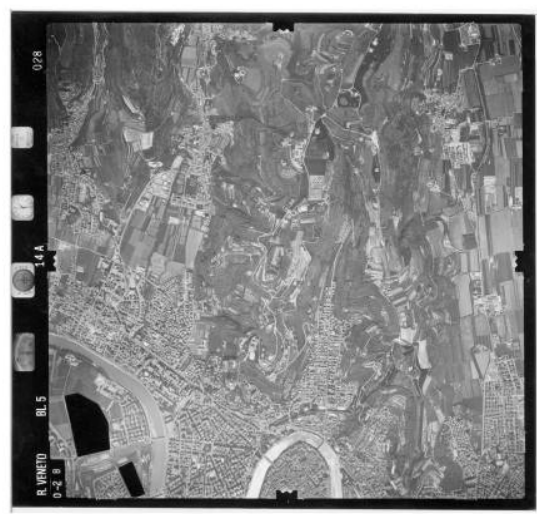

1981

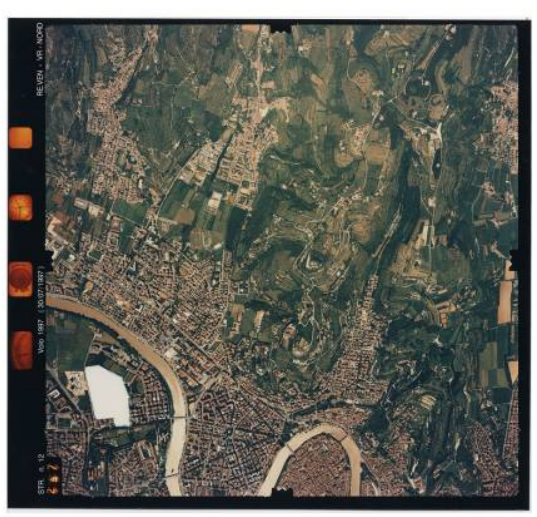

1997

Figure 1: sample images of the time series: 1954, 1981, 1997 
British Royal Air Force (RAF), the United States Army Air Force (USAAF) and the German Luftwaffe. In addition to these also the Italian Air Force flights, Military Geographical Institute and the Property Valuation Office of Florence and numerous collections donated or purchased by private companies detection aerial photography or production of cartography.

\section{THE AVAILABLE IMAGES}

As for the area of Verona, the subject of this paper, the aerial images have been made available by the Aerial Archive of University IUAV of Venice (Aerial Photo Archive of Iuav). It manages the shots are produced mainly by the Italian Military Geographical Institute (the first flights of 1929 to the flights of the 60s), the Royal Air Force (1944-45), the flight GAI (195455 with total coverage of the Veneto) and the Veneto Region (from 1978 to the most recent).

The city centre of Verona appears in 4 flights, but in the first one, made by RAF in 1945, a missing shot does not allow the necessary overlap. So the images used in this reconstruction belong to the following three flights as in Tab. 1

a) GAI Flight (Italian Aeronautics Group) of 1954-55. The flight was commissioned by the US Army Map Service and it is very important because it represents the first stereoscopic coverage of Italy. The acquisition camera was a Fairchild with a focal length of about $153 \mathrm{~mm}$. The altitude of the flight was about $5000 \mathrm{~m}$ and the mean scale of the frame is about 1: 30000 . Only 4 images have been used in the reconstruction.

b) Flight realised in 1981 by Compagnia Generale Riprese Aree of Parma on commission of Veneto Region. The flight altitude was about 2600 and the mean scale 1:17000. The images were acquired by WILD RC10 with a focal length of about $153 \mathrm{~mm}$. Photos used in reconstruction: 9

c) Flight realised in 1997 by Compagnia Generale Riprese Aree of Parma on commission of Veneto Region. The flight altitude was about 2500 and the mean scale 1:16000. The images were acquired with a focal length of about $153 \mathrm{~mm}$. Photos used in reconstruction: 15 .

The images of the flight a) and b) are black and white, while the ones of the third flight are in colour. All the images were analogue and acquired in a format $23 \times 23 \mathrm{~cm}$ and they were digitized at high resolution (600dpi) by the University Iuav of Venice.

\begin{tabular}{|lllll|}
\hline Flight & Altitude & Mean & Focal & N. of \\
& {$[\mathrm{m}]$} & scale & length & images \\
1954 & 5000 & $1: 30000$ & 153.27 & 4 \\
\hline
\end{tabular}

\begin{tabular}{|lllll|}
\hline 1981 & 2600 & $1: 17000$ & 153.15 & 9 \\
1997 & 2500 & $1: 16000$ & 153.04 & 15 \\
\hline
\end{tabular}

Tab. 1: approximate values

\section{PROCESSING OF THE HISTORICAL IMAGES}

The image processing in dense image matching software is described exhaustively in (Remondino et al, 2014). So in these paragraphs only some features, strictly connected with aerial historical images, will be highlighted.

The software used to calculate $3 \mathrm{~d}$ model is Agisoft Photoscan.

After the first automatic alignment of images, in order to georeference the model, the technical regional map (C.T:R.) of Veneto Region at scale 1:5000 has been used for all images.

The problems of this phase have already been described in (Nocerino et al, 2012) and they are related to the difficulty to pinpoint reference points in both the historical and the most recent aerial images. And frequently the identified points are inaccurate and unreliable. All this is due to the changes due to the time shift, but also to the low quality of some images, above all the oldest one.

All points used in the georeferencing are planimetric points (crossroads, property boundaries) as the border of buildings are not represented in their true elevation. However, the morphology of the city itself, with the hills immediately behind, allows to get a good three-dimensional distribution of ground control points.

The analytical results orientation are quite good (Tab. 2). They were calculated by the optimization process in PhotoScan.

\begin{tabular}{|lcl|}
\hline Flight & GCP Error $[$ pix $]$ & GCP Error $[\mathrm{m}]$ \\
1954 & 0.335 & 0.44 \\
1981 & 0.485 & 0.23 \\
1997 & 0.339 & 0.27 \\
\hline
\end{tabular}

Tab. 2: results of image orientation

\section{4}
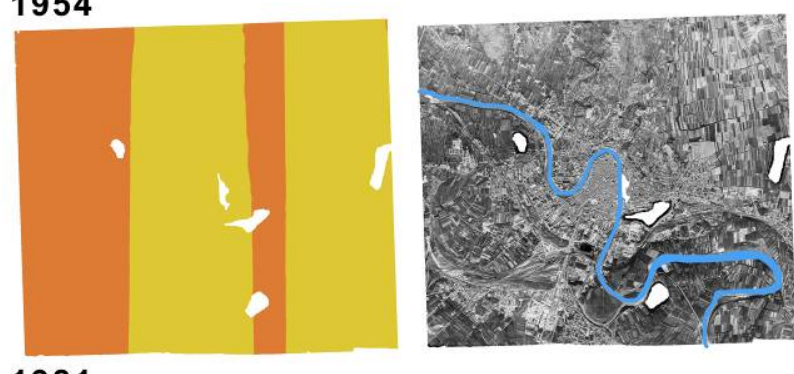

1981
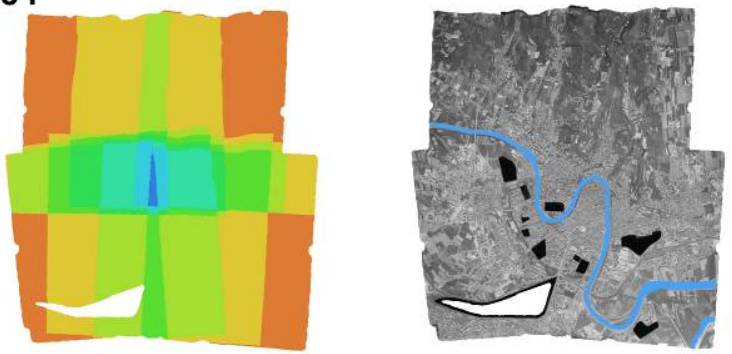

1997
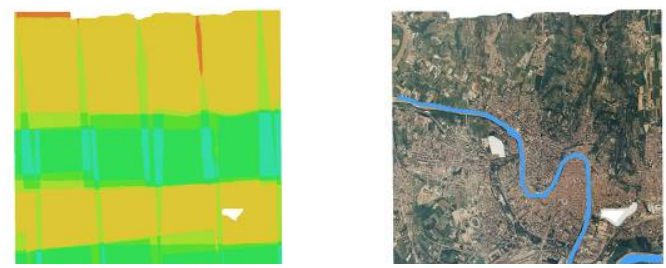

This contribution has been peeriguteiewedsults of image orientation. On the left the doi:10.5194/isprsarchives-Xap5 of the area. 


\section{COMPARISONS OF HISTORICAL 3D MODELS}

At the end of the image processing, three different models have been obtained, each one for a specific historical phase. The comparison has been split into two time interval: the first from 1954 to 1981 , the second from the 1981 to 1997 . They allow to observe the urban development of the city, the places of expansion and new urban areas for each period.

But a more interesting aspect emerged from the analytical comparison between models. The comparison between the three phases occurs by the software Cloudcompare (Cloudcompare) that allows to import different mesh and to calculate the difference as the shortest distance between the two corresponding points of the surfaces. If the difference between the surfaces is close to zero, it means that there have been no or insignificant - changes. In other areas the amount of the different is a clear indicator of changes. The value of change has a sign which helps to understand if the difference represents a new building (addiction) or a demolition (subtraction).

The comparison can be carried out as all the models have been oriented in the same reference system, the cartographic one. However, some errors remain in the process and they are caused by several factors, as seen above. In addition to image quality, the final errors depend on the uncertainty of the points extracted from the cartography and the residuals of orientation.

These errors do not affect, however, the process as it is not aimed exclusively to metrical analysis of the transformations, but especially in locating the sites affected by the biggest changes. For this reason the values of difference between surfaces should not be considered as absolute values, but as indicative parameters.

From the observation of the maps of differences, in Figure 3 , represented in false colours, some features become very evident. First of all, the gray holes are due to deficiencies in the initial images as it comes to military areas and thus have been hidden in the aerial photos.

Punctual elements, in red and blue, represent the areas with the greatest changes. The red areas towards the edges of the figure 3 are partly caused by errors on the edges of the image due to the lack of control points, and partly to the fact that those areas were not built-up in 1954 but in 1981 there were new buildings (this is why you are not able to find reference points with current cartography). In general it is evident also that the first map, with changes between 1954 and 1981, is noisier. This may be caused by the different resolution of the first dataset which influences the calculation of the difference, face to face.
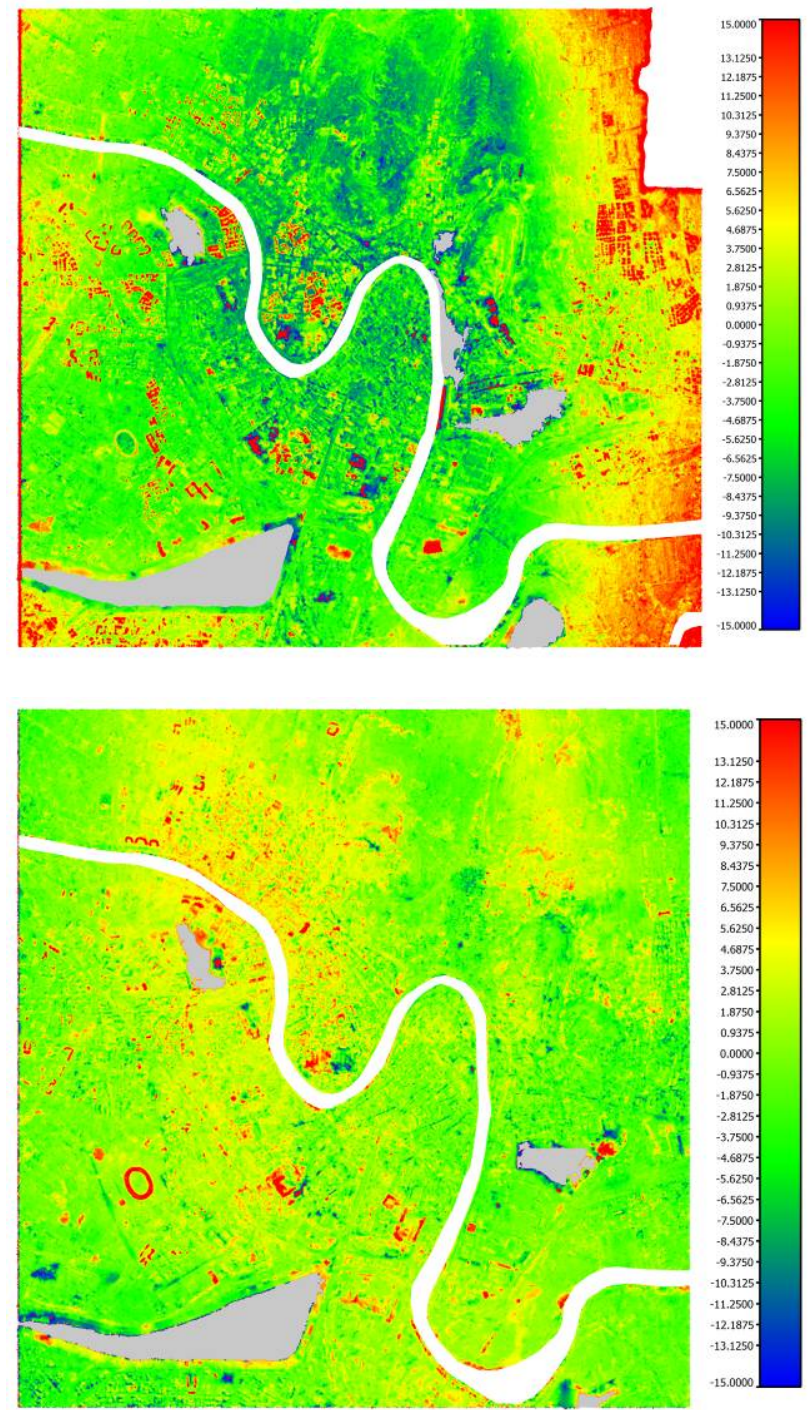

Figure 3: differences between 1981-1954. The maximum values in the scale are $+15 \mathrm{~m}$ and $-15 \mathrm{~m}$

By analyzing the points highlighted in red or blue, some cases are particularly significant. In the first map the evidences are connected above all with new building and neighbourhoods (Figure 4).

And also the area of the Bentegodi Stadium in the south west of Verona (Figure 5) shows a big transformation. The stadium was built in 1963 on an un-built area and in 1990, in occasion of the Football World Cup in Italy, a further ring was
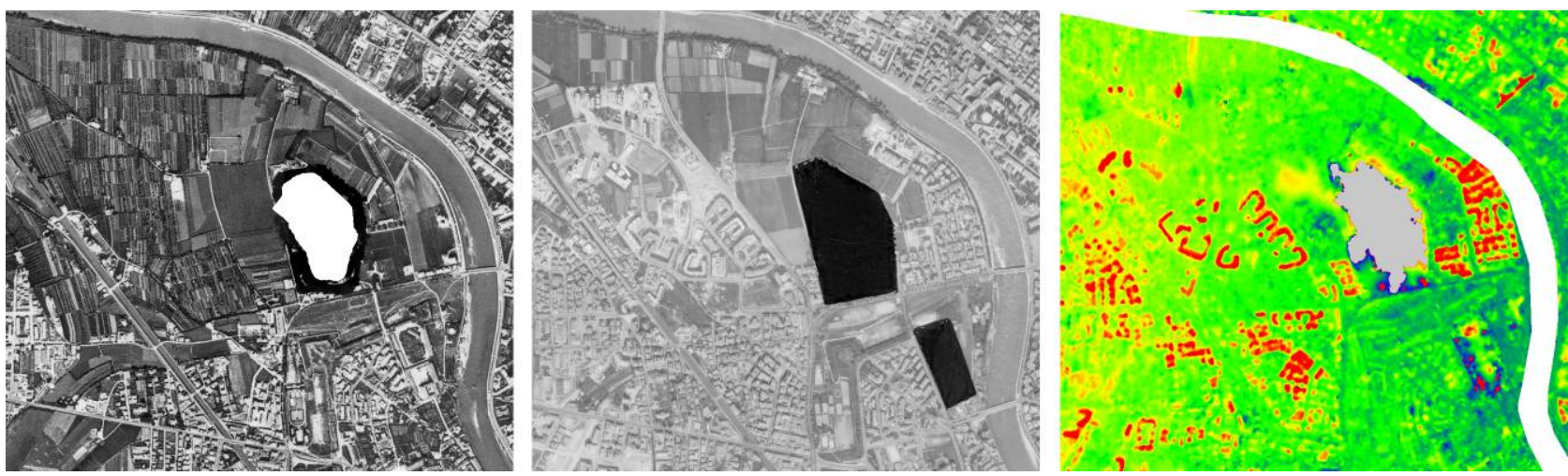

Figure 4: detail of an area: in 1954 it was unbuilt (left) in 1981 there were new buildings. On the right the difference map 
added on the top of the existing building. Because of its elliptical shape, it is easy to recognise in the urban texture its changes. By comparing the flights of 1954 and 1981 it appears that something new was built in a free area (marked by yellowred colour). Instead in the comparison between 1981 and 1997 there is the evidence of the new ring.
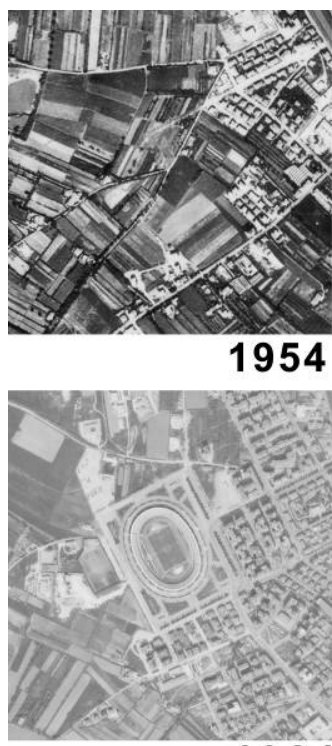

1981
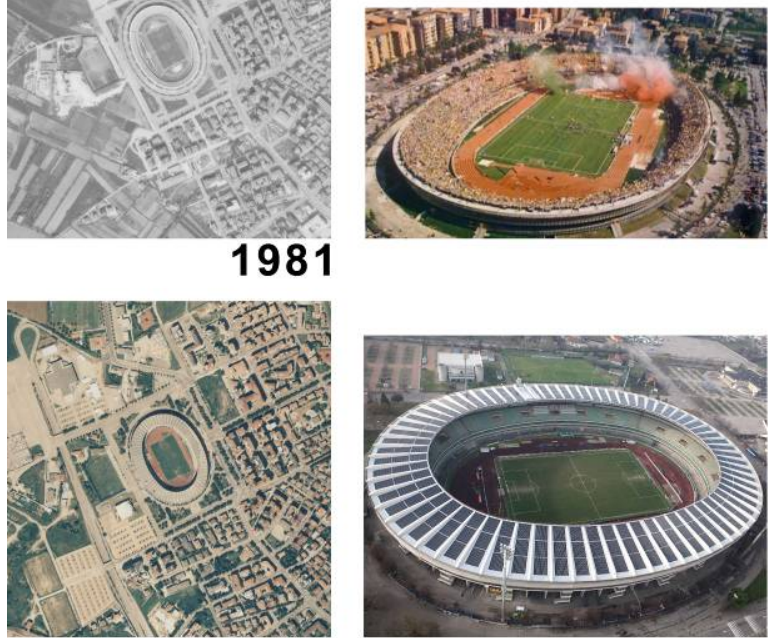

1997

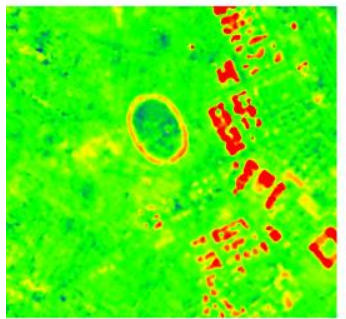

1981-1954

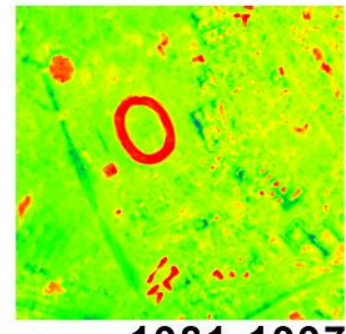

1981-1997

Figure 5: Example of city transformation documented by the comparison of $3 \mathrm{~d}$ models of different period. On the left the extraction from orthofotos of the area of the Stadio Bentegoni in Verona. On the right two images of the stadio before and after changes. At the bottom the maps of differences

\section{CONCLUSIONS}

This paper describes the application of the algorithms of dense image matching to the heritage of aerial historical images. This approach allows to enhance the documentary material of the rich Italian archives and also to reconstruct three-dimensional models of cities or parts of cities which now are missing.

The use of historical aerial photographs is favoured by the fact that it is not necessary to have all the information about the calibration of the room, which are often missing or incomplete.

The possibility to apply this approach to multiple time series, when available, allows to relate two or more historical period through a detailed comparison. The heterogeneity of photographic materials leads to results which are not always reliable in terms of metric, but certainly significant to follow the historical development of the city and its architecture.

\section{ACKNOWLEDGEMENTS}

The author are really thankful to the architect Marco Tropina who worked on these topic for his bachelor thesis and to the laboratory of cartography of University Iuav of Venice for having made available the aerial images.

\section{REFERENCES}

Aerial Photo Archive of Iuav University of Venice, http://mapserver.iuav.it/website/foto_aeree/, last visit on 25 gennuary 2015

Cloudcompare, http://www.danielgm.net/cc/, last visit on 25 gennuary 2015.

El-Hakim, S., Lapointe, J.-F., Whiting, E., 2008: Digital reconstruction and $4 \mathrm{D}$ presentation through time. Proc. SIGGRAPH.

Ferdani, D., Pescarin, S., 2011. Dal Gis alla ricostruzione 3D del paesaggio urbano antico. http://academia.edu/1884152/Dal_Gis_Alla_ricostruzione 3 D_del_paesaggio_urbano_antico.

Haala, N., 2013 : The Landscape of Dense Image Matching Algorithms. In: Fritsch, D. (Ed.): Photogrammetric Week '13, Wichmann, Berlin/Offenbach, 271-284.

Nocerino E., Menna F., Remondino F., 2012: Multi-temporal analysis of landscape and urban areas, International Archives of the Photogrammetry, Remote Sensing and Spatial Information Sciences, Volume XXXIX-B4, 2012, , XXII ISPRS Congress, 25 August - 01 September 2012, Melbourne, Australia, pp.8590 .

Patias, P., Kaimaris, D., Stylianidis, E., 2011: Change detection in historical city centers using multi-source data: the case of historical center of Nicosia - Cyprus. Proc. 23rd Int. CIPA Conference, Prague, Czech Republich.

Pavlidis G., Arnaoutoglou F., Koutsoudis A., Chamzas C., 2010: Virtual Walkthrough in a Lost Town - The Virtual Argostol", in the IASTED Computer Graphics and Imaging CGIM 2010, (Innsbruck, Austria), Feb. 17-19.

Redecker, A.P., 2008. Historical aerial photographs and digital photogrammetry for impact analyses on derelict land sites in human settlement areas. IAPRS\&SIS, Beijing, China, Vol. 37(B8), Beijing, China, pp. 5-10.

Remondino F., Del Pizzo S., Kersten T.P., Troisi S. Low-Cost and Open-Source Solutions for Automated Image Orientation, 
2012: A Critical Overview. In: Lecture Progress in Cultural Heritage Preservation. Notes in Computer Science. Proceedings of EuroMed 2012, Limassol, Cyprus, October 29 - November 3, 2012, Ioannides M., et al., Eds., Spinger-Verlag: Berlin Heildelberg, 2012, Vol. 7616, pp. 40-54;

Remondino F., Spera M. G., Nocerino E., Menna F. and Nex, F. 2014: State of the art in high density image matching. The Photogrammetric Record, 29: 144-166.

Schindler G , Dellaert F., 2012: 4D Cities: Analyzing, Visualizing, and Interacting with Historical Urban Photo Collection, "Journal of Multimedia", 2012, 7, 2, pp. 124-131.

Stefani, C., Busayarat, C., Renaudin, N., De Luca, L., Véron, P., Florenzano, M., 2011: An image-based approach for the architectural modeling of past states. IAPRS\&SIS, Vol $38(5 / \mathrm{W} 16)$. 